OPEN ACCESS

Edited by:

Diego Gil,

Museo Nacional de Ciencias

Naturales (CSIC), Spain

Reviewed by:

Lorenzo Perez-Rodriguez,

Consejo Superior de Investigaciones

Cientificas (CSIC), Spain

Jenny Qianni Ouyang,

University of Nevada, Reno,

United States

*Correspondence:

Amparo Herrera-Dueñas

bio.ahd@gmail.com

Specialty section:

This article was submitted to

Urban Ecology,

a section of the journal

Frontiers in Ecology and Evolution

Received: 20 February 2017

Accepted: 25 August 2017

Published: 12 September 2017

Citation:

Herrera-Dueñas A,

Pineda-Pampliega J,

Antonio-García MT and Aguirre JI

(2017) The Influence of Urban

Environments on Oxidative Stress

Balance: A Case Study on the House

Sparrow in the Iberian Peninsula.

Front. Ecol. Evol. 5:106

doi: 10.3389/fevo.2017.00106

\section{The Influence of Urban Environments on Oxidative Stress Balance: A Case Study on the House Sparrow in the Iberian Peninsula}

\author{
Amparo Herrera-Dueñas ${ }^{1 *}$, Javier Pineda-Pampliega ${ }^{1}$, María T. Antonio-García ${ }^{2}$ and \\ José I. Aguirre ${ }^{1}$ \\ 1 Evolution and Conservation Biology, Department of Zoology and Physical Anthropology, Faculty of Biology, Complutense \\ University of Madrid, Madrid, Spain, ${ }^{2}$ Department of Animal Physiology II, Faculty of Biology, Complutense University of \\ Madrid, Madrid, Spain
}

The House Sparrow is a globally distributed species and is closely associated with anthropised environments. They are well-adapted to urban life; therefore the decline of their populations in Europe represents an unexpected event that demands an investigation into its causes. Causes that have promoted this decline are not well-known, but one of the highlighted hypotheses is an increase of oxidative stress linked to the toxicity of pollution in urban areas. From an ecophysiological perspective, oxidative damage, antioxidant defense, and oxidative balance are considered reliable indicators of environmental stressors such as pollutants. To carry out this study, blood samples were collected from House Sparrows in three different habitats that varied in terms of urbanization degree: urban, suburban, and rural; during the winter and breeding season. According to our results, urban sparrows showed higher levels of oxidative damage and higher activity of antioxidant enzymes, but lower antioxidant capacity in comparison with the rural birds; and these differences especially increase during the breeding season. The maintenance of oxidative balance increases in an urban environment in comparison to a rural one; we suggest that the high level of pollution and the poor quality diet linked to urban environments. The breeding season is expected to be particularly challenging for the oxidative balance of urban birds, when the reallocation of resources between self-maintenance and reproduction may be critical due to the scarcity of antioxidants found in urban areas. This study may contribute to determining the causes of the population decrease of House Sparrows in cities.

Keywords: urbanization, biomarker, pollution, antioxidant defense, oxidative damage, bird

\section{INTRODUCTION}

Urban areas have been growing rapidly over the last several decades, and it is expected that they will continue to expand at the expense of natural and rural habitats. From an ecological perspective, urban environments present some novel challenges for birds, such as new predators, new flora, human presence, unique food resources, and high levels of chemical, light, and acoustic pollution (Gaston, 2010; Lepczyck and Warren, 2012; Forman, 2013; Gil and Brumm, 2014). However, these 
novel and potentially stressful conditions generated by urban environment processes have also provided new opportunities for certain species to gain an ecological advantage by exploiting city resources (Lepczyck and Warren, 2012; Costantini et al., 2014). Such resources are characterized by lower predation rates (Evans et al., 2015), higher environmental temperatures (Tryjanowski et al., 2015), lower competition for resources (Kark et al., 2007), and a constant, abundant, and more predictable food resources supply, in comparison with the surrounding non-anthropogenic areas (Shochat, 2004; Oro et al., 2013; Andersson et al., 2015; Tryjanowski et al., 2015; Marzluff, 2016).

The House Sparrow (Passer domesticus L.) is one of these urban exploiter species, meaning that it dominates highly urbanized environments. It is the most ubiquitous and globally distributed bird, probably due to its ecological tolerance that allows them to cope with urban environments: they are generalist, granivorous, gregarious, and sedentary, they nest in cavities, they are unbothered by human presence, and they are able to explore new feeding sources (Anderson, 2006; Kark et al., 2007; Evans et al., 2011). However, in the last few decades, urban populations of House Sparrow have significantly dropped, especially in the highly developed regions of Western Europe (De Laet and Summers-Smith, 2007; Peach et al., 2008; Shaw et al., 2008; De Coster et al., 2015). There is no consensus on the reason for such a decline, but the increasing level of pollution has been highlighted as one of the main driving factors (Shaw et al., 2008; Herrera-Dueñas et al., 2014).

The atmosphere of urban areas tends to accumulate high concentrations of carbon dioxide $\left(\mathrm{CO}_{2}\right)$, nitrous oxides $\left(\mathrm{NO}_{\mathrm{x}}\right)$, sulfur dioxide $\left(\mathrm{SO}_{2}\right)$, ozone $\left(\mathrm{O}_{3}\right)$, heavy metals and other suspended particulate matters (PM). In cities, these pollutants are mainly derived by burning fossil fuels (Grimm et al., 2008; Gaston, 2010), representing an environmental risk from human to ecosystem levels (Forman, 2013). In relation to human health, a correlation has been described between the level of pollution and higher human mortality rates, mainly associated with cancer, asthma and cardiovascular disorders (Kelly, 2003). To date, deleterious effects on wildlife are less well-known, but pollution has been related to reproductive performance, lower survival rates and shorter lifespans (Isaksson, 2010; Koivula and Eeva, 2010; Salmón et al., 2016). One trait that has been highlighted as responsible for the toxicity of urban pollutants is their high reactivity to biomolecules (Koivula et al., 2011). Therefore, oxidative stress has been described as an underlying mechanism by which urban pollutants cause deleterious effects in living organisms (Isaksson, 2010).

Oxidative stress has been defined as the occurrence of enzymatic and non-enzymatic antioxidants that cannot fully neutralize the free radicals produced in the cells of living organisms. Free radicals are commonly generated as a by-product of normal metabolic processes. Hence all aerobic organisms have evolved multiple defense lines to prevent or counteract the toxicity of reactive by-products, ranging from antioxidant enzymes to low molecular weight endogenous antioxidants (i.e., GSH), complemented by some dietary antioxidant such as carotenoids or vitamins (Halliwell, 2007). Under pro-oxidant conditions, the unquenched free radicals remain in the system long enough to cause further oxidation reactions (Monaghan et al., 2009). Such reactions may damage macromolecules, such as lipids, proteins, and DNA. Severe accumulation of oxidative damage in these molecules leads to cellular dysfunction or apoptosis, which triggers disease and age-related degeneration (Costantini and Verhulst, 2009; Isaksson, 2015). This supports the hypothesis that the resistance to oxidative stress is a key cellular mechanism to cope with urban pollutants, so the capacity to quench the oxidative damage has been highlighted as a critical adaptation to life in the city (Costantini et al., 2014).

The levels of oxidative stress in organisms could also vary with developmental stage, environmental condition, and level of activity (Isaksson, 2015). Reproduction could increase oxidative stress as an inevitable consequence of increased reproductive effort (Romero-Haro et al., 2016) and/or because the developing offspring consume antioxidants otherwise allocated to selfmaintenance (Alonso-Alvarez et al., 2004; Moller et al., 2010; Berglund et al., 2014). Therefore, oxidative stress may have a dramatic effect on bird fitness during the breeding season.

Regarding the roles of these antioxidants in maintaining the oxidative balance, four different scenarios could be described: (I) low oxidative damage due free radicals being quenched by the excess supply of antioxidants (endogenous or diet-provided); the maintenance of the oxidative balance in this case is not costly for self-maintenance of individuals, and resources can be reallocated to other functions (i.e., reproduction). (II) Oxidative damage is in balance with antioxidant availability; therefore, there is no surplus of resources, but self-maintenance is not yet costly for individuals. (III) Oxidative damage persists and to counteract it, the individual may increase its antioxidant capacity by up-regulating some antioxidant enzymes; this entails a cost because some resources must be diverted from self-maintenance. (IV) Oxidative damage is uncontrolled; the antioxidant defenses have been overwhelmed and the survival of the individual is compromised (Costantini and Verhulst, 2009; Monaghan et al., 2009) (Figure 1).

We predict that the first scenario will correspond to areas with a low degree of urbanization and therefore to lower levels of pollution (such as the rural ones); the second one will correspond to mild stressor environment (such as the suburban areas); whereas the third scenario will correspond to highly urbanized areas, where the high level of pollution may be a challenge for antioxidant defenses. We will explore the oxidative stress balance during winter, but also during the breeding season, when adults are reproducing.

\section{MATERIALS AND METHODS}

\section{Area Characterization}

House sparrows were sampled at six locations of central Iberian Peninsula: Plasenzuela, a small village $230 \mathrm{~km}$ away from big cities such as Madrid (PZ: $39^{\circ} 22^{\prime} 39^{\prime \prime} \mathrm{N} ; 6^{\circ} 02^{\prime} 57^{\prime \prime} \mathrm{W}$ and $427 \mathrm{~m}$ altitude), Olmeda de las Fuentes, another small village $50 \mathrm{~km}$ East of Madrid located in a traditional agricultural area of the region (OF: $40^{\circ} 21^{\prime} 38^{\prime \prime} \mathrm{N} ; 3^{\circ} 12^{\prime} 23^{\prime \prime} \mathrm{W}$ and $794 \mathrm{~m}$ altitude), El Escorial, a small town $50 \mathrm{~km}$ Northwest of Madrid with typical suburban structure (i.e., family houses 


\section{Scenario I}

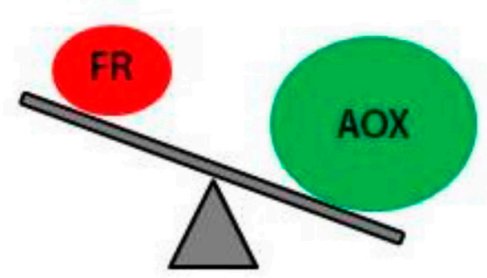

Rural areas

\section{Pollution $\quad$ Quality diet}

\section{Scenario II}

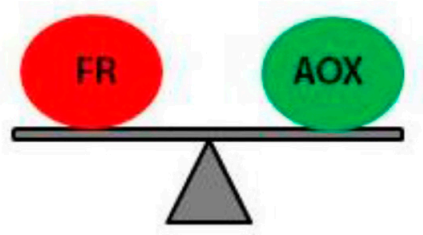

Suburban areas

$=$ Pollution $=$ Quality diet

\section{Scenario III}

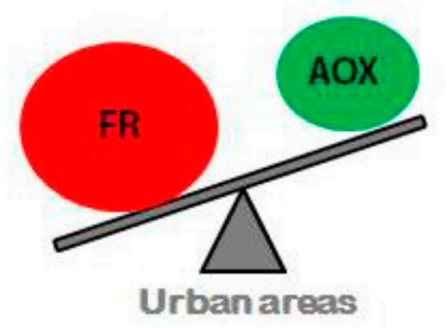

\section{$\uparrow$ Pollution $\downarrow$ Quality diet}

FIGURE 1 | The different scenarios (I, II, and III) depending on the relationship between the environmental stressors (such as pollution) and dietary antioxidants (the scenario IV has been excluded due to it is not expected to be related to urban environments). FR (red color) represents free radical production: intrinsic + induced by environmental stressors; and AOX (green color) represents a number of antioxidants available: endogenous + antioxidant enzymes + dietary antioxidants.

with individual gardens) (EE: $40^{\circ} 34^{\prime} 55^{\prime \prime} \mathrm{N} ; 4^{\circ} 07^{\prime} 41^{\prime \prime} \mathrm{W}$ and $1.030 \mathrm{~m}$ altitude), Las Matas, a small town $25 \mathrm{~km}$ Northwest of Madrid in an area with a similar suburban structure (LM: $40^{\circ} 33^{\prime} 41^{\prime \prime} \mathrm{N} ; 3^{\circ} 53^{\prime} 56^{\prime \prime} \mathrm{W}$ and $720 \mathrm{~m}$ altitude), Fuenlabrada, a town $25 \mathrm{~km}$ South of Madrid in the traditional industrial area of the region (FB: $40^{\circ} 17^{\prime} 07^{\prime \prime} \mathrm{N} ; 3^{\circ} 48^{\prime} 35^{\prime \prime} \mathrm{W}$ and $650 \mathrm{~m}$ altitude) and Madrid city center, one of the biggest cities of the Mediterranean region (MD: $40^{\circ} 25^{\prime} 03^{\prime \prime} \mathrm{N} ; 3^{\circ} 42^{\prime} 42^{\prime \prime} \mathrm{W}$ and $670 \mathrm{~m}$ altitude). These sampling areas were chosen because they show strong differences in their landscape and their anthropization degree. In addition they showed high bird densities due to the constant food supply: a horse stable in MD and a farmschool in FB, gardens with hen cages in the suburban areas, and a sheep farm in OF and a poultry farm in PZ. Therefore, it was expected that birds would not show symptoms of starvation and their condition would vary depending on other environmental stressors such as pollutants, and the availability of essential nutritional complements that they should intake (i.e., insects).

One of the most reliable indicators of the urbanization process is land cover (Marzluff, 2008; Gaston, 2010; Niemelä, 2011; Lepczyck and Warren, 2012), which can be complemented by the population density (Marzluff, 2008; Lepczyck and Warren, 2012) and air quality (Gaston, 2010; Forman, 2013). Data referring to air quality $\left(\mathrm{NO}_{2}\right.$ and $\left.\mathrm{PM}_{10}\right)$ were collected from the European Environmental Agency (EEA), and data referring to human density and land uses were collected from the Spanish Statistics Institute (INE) and the Information System for Land Uses in Spain (SIOSE), which had a resolution of $0.05 \mathrm{~km}^{2}$ (Table 1). The percentage of each land use (industrial, housing, recreation urban areas, agricultural and natural) was calculated in a $4 \mathrm{~km}^{2}$ area around the sample point using Photoshop (Figure 2), based on the species movements described by Anderson (2006).

\section{Bird Sampling}

This study was carried out in accordance with all applicable institutional and national guidelines for the care and use of animals. Bird sampling was performed with permissions from landowners and the regional Consejería de Medioambiente de la Comunidad de Madrid (REFS: JML/ecc-10/038121.9/13; IPZ/ecc-10/068353.9.14; and Delegación de Medioambiente de la Junta de Extremadura REFS: EJD/jmca-CN0004/14/ACA).

A total of 210 adult House Sparrows were captured during the winter period (December 2013 to February 2014) and the breeding season (April 2014 to June 2014) in the different habitats (Table 2). The birds were trapped with mist nests or traps and ringed. They were weighed $( \pm 0.1 \mathrm{~g})$, their tarsus length was measured $( \pm 0.1 \mathrm{~mm})$ and blood samples were collected. Birds were captured in mist nets and retained until manipulation in cloth bags to keep them safe and calm. All sampled birds were released unharmed at the site of capture after manipulation.

Blood samples $(\sim 0.2 \mathrm{ml})$ were collected $(\sim 15 \mathrm{~min}$ after capture) by jugular venepuncture using $30 \mathrm{G}$ needles. The blood was collected in heparinized tubes and kept at $4^{\circ} \mathrm{C}$ before transporting to the laboratory (maximum $4 \mathrm{~h}$ ). Blood was centrifuged for $10 \mathrm{~min}$ at $1,800 \times \mathrm{g}(10,000 \mathrm{rpm})$ to separate the erythrocyte pellet and plasma, and was divided into aliquots to avoid freeze-thaw cycles. All samples were stored at $-80^{\circ} \mathrm{C}$ until use. 


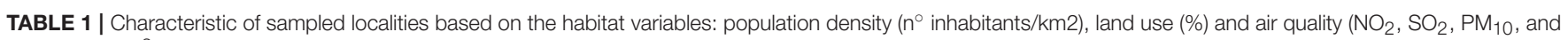
$\mathrm{PM}_{2.5}$ in $\left.\mu \mathrm{g} / \mathrm{m}^{3}\right)$.

\begin{tabular}{|c|c|c|c|c|c|c|c|c|c|c|c|}
\hline Habitat & Site & Population density & Housing land & Recreation land & Industrial land & Agricultural land & Natural land & $\mathrm{NO}_{2}$ & $\mathrm{SO}_{2}$ & $\mathrm{PM}_{10}$ & $\mathrm{PM}_{2.5}$ \\
\hline Urban & MD & 5,225 & 58.88 & 38.34 & 1.12 & 0.00 & 0.00 & 37.95 & 5.03 & ND & ND \\
\hline Urban & $\mathrm{FB}$ & 4,960 & 33.75 & 8.27 & 13.23 & 34.53 & 8.72 & 31.11 & ND & 28.26 & ND \\
\hline Suburban & $\mathrm{LM}$ & 1,040 & 31.35 & 3.96 & 0.23 & 0.87 & 60.89 & 27.69 & ND & ND & 13.4 \\
\hline Suburban & $\mathrm{EE}$ & 222 & 17.26 & 7.91 & 0.59 & 9.76 & 58.83 & 22.66 & ND & 23.21 & ND \\
\hline Rural & OF & 20 & 0.97 & 0.19 & 0.00 & 54.19 & 37.65 & 7.03 & ND & 17.30 & ND \\
\hline Rural & $P Z$ & 14 & 0.47 & 0.03 & 0.00 & 41.47 & 56.18 & 4.97 & 2.54 & 16.05 & ND \\
\hline
\end{tabular}
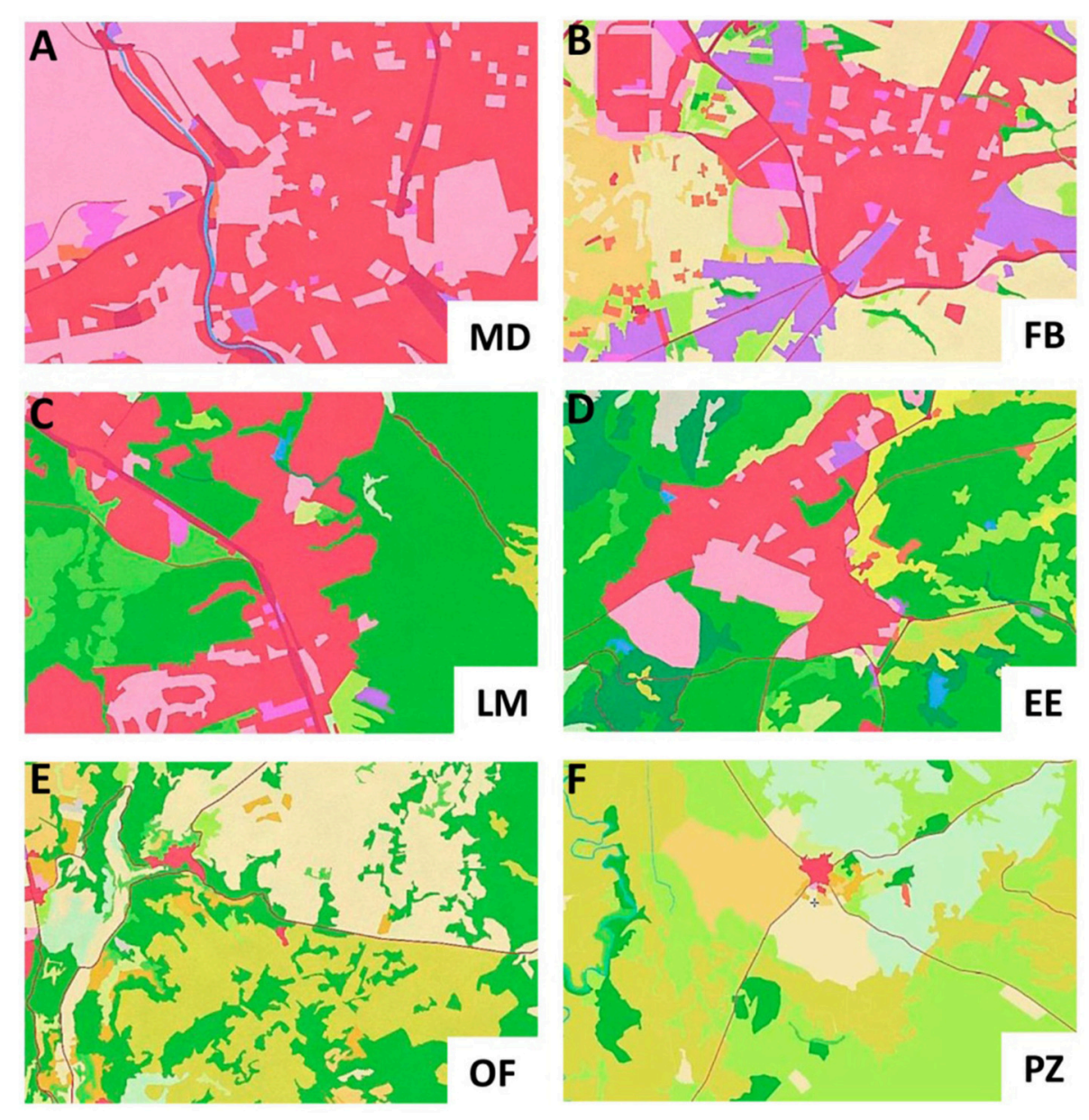

FIGURE 2 | Images used for calculating the land uses at each sample point: Madrid city (A), Fuenlabrada (B), Las Matas (C), El Escorial (D), Olmeda de las Fuentes (E), and Plasenzuela (F). The dark pink areas represent housing and roads, the light pink represent urban parks and recreation facilities, the purple ones represent industrial areas, the yellowish ones represent agricultural lands and the greenish ones represent natural areas like forest or field.

\section{Oxidative Stress Biomarkers}

Due to the complex relationship between the different elements constituting the oxidative stress system, at least several oxidative damage and antioxidant capacity biomarkers must be determined to correctly interpret the results (Monaghan et al., 2009). To evaluate the oxidative stress balance of House Sparrows, we determined the antioxidant capacity of plasma, as well as the oxidative damage and activity of some antioxidant enzymes in the erythrocytes.

The total antioxidant capacity (TAC) of plasma is a reliable biomarker to describe the global oxidant/antioxidant balance of individuals. This was determined spectrophotometrically using the ferric reducing ability of plasma (FRAP) method described by Benzie and Strain (1996), with the slight modifications described by Hargitai et al. (2012). This method is based on the ferric 
TABLE 2 | Number of individuals captured per locality and season

\begin{tabular}{|c|c|c|c|c|c|c|c|}
\hline & & \multicolumn{2}{|c|}{ Rural } & \multicolumn{2}{|c|}{ Suburban } & \multicolumn{2}{|c|}{ Urban } \\
\hline & & PZ & OF & EE & LM & FB & MD \\
\hline \multirow[t]{2}{*}{ Winter } & Males & 12 & 12 & 12 & 10 & 7 & 26 \\
\hline & Females & 9 & 11 & 11 & 11 & 13 & 14 \\
\hline \multirow[t]{2}{*}{ Breeding season } & Males & 8 & ND & ND & 19 & ND & 8 \\
\hline & Females & 11 & & & 11 & & 5 \\
\hline
\end{tabular}

reduction: $\mathrm{Fe}^{3+}$ (ferric) to $\mathrm{Fe}^{2+}$ (ferrous) ion reduction at low $\mathrm{pH}$ causes the formation of the colored ferrous-tripyridyltriazine ( $\mathrm{Fe}^{2+}$-TPTZ) complex. Briefly, $20 \mu$ l of diluted plasma was mixed with $150 \mu \mathrm{l}$ of ferrous ion and TPTZ at low $\mathrm{pH}$ and incubated for 20 min. FRAP values were obtained by comparing the absorbance change at $593 \mathrm{~nm}$ in test reaction mixtures with those containing $\mathrm{Fe}^{2+}$ in known concentration. The parameter was corrected with the uric acid value (Costantini, 2011), which was spectrophotometrically measured at $520 \mathrm{~nm}$ by the uricase method (Fossati et al., 1980) using a commercial kit from Spinreact ${ }^{\circledR}$. The intra-assay and inter-assay coefficient variation $(\mathrm{CV})$, respectively, were 1.72 and $1.97 \%$.

The oxidative damage was determined in the lipid and erythrocyte proteins. The lipid peroxidation was estimated spectrophotometrically by the thiobarbituric acid (TBA) reaction with malondialdehyde (MDA), a by-product of the peroxidation of membrane lipids according to the method of Ohkawa et al. (1979). This method is controversial since it has been considered less accurate in comparison with the quantification based on the HPLC method, due to overestimation of the results (Grotto et al., 2009). Although other authors still consider spectrophotometry as a reliable methodology for the determination of lipid peroxidation (Zeb and Ullah, 2016) and we still use it due to technical reasons, this result is less reliable and it should be interpreted carefully and together with other biomarkers of oxidative damage. Briefly, $250 \mu \mathrm{l}$ of the erythrocyte homogenate was reacted with $500 \mu$ l of TBA solution (pH 3.5), the mixture was heated at $80^{\circ} \mathrm{C}$ for $60 \mathrm{~min}$. Under these conditions, the TBA-reactive substances (mainly MDA) reacted with TBA to yield TBA-MDA adducts, which were detected at $532 \mathrm{~nm}$. The concentration of the chromophore was calculated from a calibration curve prepared with tetramethoxypropane (TMP) solution. The intra-assay and inter-assay CVs, respectively, were 2.89 , and $7.24 \%$. The protein oxidation was estimated spectrophotometrically by 2,4-dinitrophenyl hydrazine (DNPH) reaction with the carbonyl groups, by-products of the oxidation of proteins, using the method by Reznick and Packer (1994) with the modifications describe by Arnal et al. (2011). Briefly, $100 \mu l$ of the erythrocyte homogenate was subjected to a reaction with $100 \mu \mathrm{l}$ of DNPH in acid solution of $\mathrm{HCl}$ at $37^{\circ} \mathrm{C}$ in the dark for $30 \mathrm{~min}$; the corresponding hydrazone derivatives were revealed after the addition of $200 \mu \mathrm{l}$ of $\mathrm{NaOH}$ and measured at $505 \mathrm{~nm}$. The concentration of carbonyls was calculated from a calibration curve prepared with a stock solution of sodium pyruvate. The intra-assay and inter-assay CVs, respectively, were 2.56 and $8.67 \%$.
The enzymatic antioxidant system capacity was determined by the evaluation of glutathione peroxidase (GPX) and superoxide dismutase (SOD) activity. The activity of GPX was measured spectrophotometrically by reduction of 5, 5'-dithiobis, 2 nitrobenoic acid (DTNB) for the activity of GPX using the glutathione (GSH) of the cells, as described by Moin (Tkachenko et al., 2014). The reaction was read at $412 \mathrm{~nm}$ every $30 \mathrm{~s}$ for $3 \mathrm{~min}$. Activity is expressed as $\mu \mathrm{mol} \mathrm{GSH} / \mathrm{min} / \mathrm{ml}$. The intraassay and inter-assay CVs, respectively, were 6.92 and $7.69 \%$. The activity of SOD was measured spectrophotometrically by the containment of autoxidation of pyrogallol, as described by Marklund and Marklund (1974). The reaction was read at $420 \mathrm{~nm}$ every $60 \mathrm{~s}$ for $5 \mathrm{~min}$. Activity is expressed as $\mathrm{U} / \mathrm{ml}$. The intra-assay and inter-assay CVs, respectively, were 7.39 and $8.74 \%$.

Samples were randomly distributed among plates. All the assays were running in duplicate. The same assay was running in all the samples during the same lab session.

\section{Data Analysis}

The body condition index of individuals was calculated using the scaled mass index (SMI) recommended by Peig and Green (2009) for small animals. The SMI has been calculated according to the equation:

$$
\mathrm{SMI}=\mathrm{M}_{\mathrm{i}} \times\left(\frac{\mathrm{L}_{0}}{\mathrm{~L}_{\mathrm{i}}}\right)^{\mathrm{b}_{\mathrm{SMA}}}
$$

where $\mathrm{M}_{\mathrm{i}}$ and $\mathrm{L}_{\mathrm{i}}$ are the body mass and tarsus length of individual $\mathrm{I}$, respectively; $\mathrm{L}_{0}$ is the arithmetic mean value of tarsus length for the study population; and $\mathrm{b}_{\mathrm{SMA}}$ is the scaling exponent estimated by the standardized major axis (SMA) regression of $\ln \mathrm{M}$ on $\ln \mathrm{L}$.

In order to evaluate the effect of habitat and season, we used a general linear mix model (GLMM). Fix factors included in the whole model were habitat (rural, suburban, or urban), season (winter or breeding) and their interaction (habitat $\times$ season) and the capture locality as random factor. In all analyses, sex (male or female) and body condition (as SMI) were also included as covariates. A post-hoc assay (Tukey's HSD) was performed only for traits regarding habitat. All the models were tested for residual normality.

All results are expressed as means \pm standard error of means $(\overline{\mathrm{X}} \pm$ S.E.M.). All analyses were performed in R-Studio version 3.3.1 using the lme4, the lmerTest, and the lsmeans packages.

\section{RESULTS}

\section{Area Characterization}

Although the characterization of urban landscapes is complex due to its heterogeneity and huge variation between regions, the sampling sites showed a clear pattern in terms of air quality, land use, and population density. We were able to clearly disentangle three different categories (Marzluff, 2008; Gaston, 2010; Forman, 2013): (I) urban, a completely anthropic landscape typical of big cities or town centers, usually characterized by a high percentage of ground occupied by buildings and pavements mixed with facilities (such as shops, museum, schools, hospitals, and sportcenters), with high population densities. These areas are usually associated with high pollutant levels due to traffic and heater 
emissions. (II) Suburban, residential areas located at the edge of big cities and/or smaller towns. It is also characterized by a high building density, but the most common structures are houses with gardens so the percentage of green areas is usually higher and better distributed than in urban areas. In addition, non-anthropized areas, such as forests or fields, contribute to the landscape. The quality of the air usually improves in these areas because of the lower population density; however, it is still high in comparison with rural settlements. Finally, (III) rural, villages, or even smaller settlements embedded in natural or agricultural landscapes. In this case, the percentage of buildings and roads is lower when compare to green areas. Its population density is sparse and the quality of air is good according to the standard.

\section{Body Condition and Oxidative Stress Biomarkers}

The body condition, calculated as SMI, showed a significant interaction between habitat and season $\left[F_{(2,113.02)}=5.92\right.$; $p=0.003]$, driven by the fact that the SMI of urban birds had a trend for being lower during the breeding season compared to winter $(t=-2.86 ; p=0.052)$, whereas rural birds showed the opposite trend (they were bigger during the breeding season). In the suburban population, SMI was similar in both seasons. Overall, the SMI of rural birds was higher in comparison with the other population (Figure 3, Table 3).

In relation to oxidative stress biomarkers, the season did not show any effects, while the habitat seemed to play a main role. Only in the case of TAC did the model show a significant
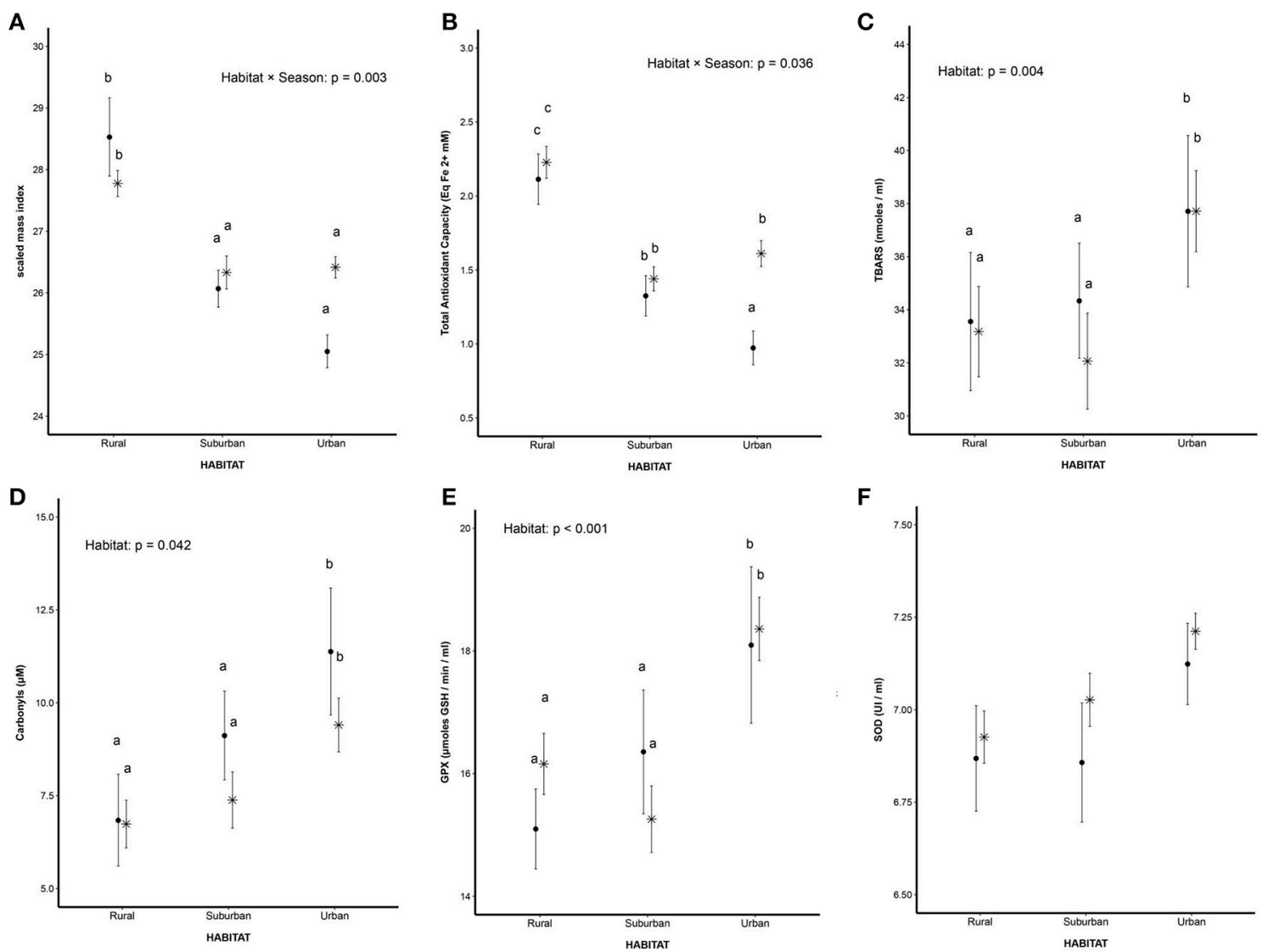

FIGURE 3 | Body condition and oxidative stress biomarkers analyzed. (A) Body condition calculated as scaled mass index (SMI). Values are expressed as mean \pm S.E.M. Asterisk $\left(^{*}\right)$ represent individuals captured at winter and filled circles (•) represent individuals captured during the breeding season. Letters indicate statistical difference: means with the same letter are not statistically different (Tukey's tests, $p \leq 0.05$ ); (B) Total antioxidant capacity calculated as FRAP. Values are expressed as mean \pm S.E.M. Asterisk (*) represent individuals captured at winter and filled circles (•) represent individuals captured during the breeding season. Letters indicate statistical difference: means with the same letter are not statistically different (Tukey's tests, $p \leq 0.05$ ); (C) Lipid damage calculated as TBARS. Values are expressed as mean \pm S.E.M. Asterisk (*) represent individuals captured at winter and filled circles (•) represent individuals captured during the breeding season. Letters indicate statistical difference: means with the same letter are not statistically different (Tukey's tests, $p \leq 0.05$ ); (D) Protein damage calculated as concentration of carbonyls groups. Values are expressed as mean \pm S.E.M. Asterisk (*) represent individuals captured at winter and filled circles (•) represent individuals captured during the breeding season. Letters indicate statistical difference: means with the same letter are not statistically different (Tukey's tests, $p \leq 0.05$ ); (E) Glutathione peroxidase activity (GPX). Values are expressed as mean \pm S.E.M. Asterisk (*) represent individuals captured at winter and filled circles (•) represent individuals captured during the breeding season. Letters indicate statistical difference: means with the same letter are not statistically different (Tukey's tests, $p \leq 0.05)$; (F) Superoxide dismutase activity (SOD). Values are expressed as mean \pm S.E.M. Asterisk (*) represent individuals captured at winter and filled circles (•) represent individuals captured during the breeding season. 
TABLE 3 | The model for each dependent variable when exploring the effect of the habitat and season on body condition and oxidative stress biomarkers.

\begin{tabular}{|c|c|c|c|c|}
\hline $\begin{array}{l}\text { Dependent } \\
\text { variable }\end{array}$ & Source of variation & d.f. & $\boldsymbol{F}$ & $p$-value \\
\hline \multicolumn{5}{|l|}{ BODY CONDITION } \\
\hline \multirow{3}{*}{$\begin{array}{l}\text { Scaled mass index } \\
\text { (SMI) }\end{array}$} & Habitat & $2,2.51$ & 14.04 & 0.043 \\
\hline & Season & $1,125.25$ & 0.80 & 0.371 \\
\hline & Habitat $\times$ Season & $2,113.02$ & 5.92 & 0.003 \\
\hline \multicolumn{5}{|c|}{ OXIDATIVE BALANCE } \\
\hline \multirow{3}{*}{$\begin{array}{l}\text { Total Antioxidant } \\
\text { Capacity (FRAP) }\end{array}$} & Habitat & $2,2.92$ & 17.14 & 0.024 \\
\hline & Season & $1,51.79$ & 6.04 & 0.017 \\
\hline & Habitat $\times$ Season & $2,37.02$ & 3.63 & 0.036 \\
\hline \multicolumn{5}{|c|}{ OXIDATIVE DAMAGE } \\
\hline \multirow{2}{*}{$\begin{array}{l}\text { Lipid peroxidation } \\
\text { (TBARS) }\end{array}$} & Habitat & 2,177 & 5.68 & 0.004 \\
\hline & Season & 1,177 & 0.35 & 0.549 \\
\hline \multirow{2}{*}{$\begin{array}{l}\text { Protein oxidation } \\
\text { (Carbonyls) }\end{array}$} & Habitat & 2,123 & 3.23 & 0.042 \\
\hline & Season & 1,123 & 2.04 & 0.154 \\
\hline \multicolumn{5}{|c|}{ ANTIOXIDANT DEFENSES } \\
\hline \multirow{2}{*}{$\begin{array}{l}\text { Glutathione } \\
\text { peroxidase activity } \\
\text { (GPX) }\end{array}$} & Habitat & 2,141 & 9.22 & $<0.001$ \\
\hline & Season & 1,141 & 0.05 & 0.815 \\
\hline \multirow{2}{*}{$\begin{array}{l}\text { Superoxide } \\
\text { dismutase activity } \\
\text { (SOD) }\end{array}$} & Habitat & $2,2.78$ & 2.83 & 0.530 \\
\hline & Season & $1,84.76$ & 0.39 & 0.213 \\
\hline
\end{tabular}

They were corrected by covariates (sex in all cases, and sex and body condition in oxidative stress biomarkers). Significant factors $(p \leq 0.05)$ have been highlighted in bold. Non-significant interactions were excluded from the model.

interaction between habitat and season $\left[F_{(2,37.02)}=3.63\right.$; $p=0.036]$ : overall, the rural birds showed a higher antioxidant capacity in comparison with the suburban and urban birds. The urban birds showed a significantly lower antioxidant capacity during the breeding season compared to winter $(t=-3.34$; $p=0.012$ ) (Figure 3, Table 3).

Regarding oxidative damage, lipid peroxidation was significantly higher in urban birds in comparison with the suburban $(t=2.65 ; p=0.023)$ and rural birds $(t=3.12$; $p=0.005)\left[F_{(2,177)}=5.68 ; p=0.004\right]$ (Figure 3, Table 3). The oxidation of proteins was also higher in the urban population compared to the suburban $(t=2.49 ; p=0.036)$ and rural population $(t=1.54 ; p=0.027)\left[\mathrm{F}_{(2,123)}=3.23\right.$; $\left.p=0.042\right]$ (Figure 3, Table 3).

The activity of the antioxidant defense system was also influenced by habitat. The activity of GPX was significantly higher in urban birds compared to suburban $(t=3.75 ; p<0.001)$ and rural birds $(t=3.68 ; p=0.001)\left[F_{(2,144)}=9.22 ; p<0.001\right]$ (Figure 3, Table 3). However, the activity of SOD did not show significant differences $\left[F_{(2,151)}=4.88 ; p=0.008\right]$ (Figure 3, Table 3).

\section{DISCUSSION}

We found that urban sparrows showed higher levels of oxidative damage and a higher activity of antioxidant enzymes, but a lower antioxidant capacity in comparison with the rural birds. Some of these differences are especially increased during the breeding season.

According to our predictions, the low oxidative damage scenarios (I and II) matches the situation found in the rural and suburban populations, respectively. Oxidative damage seems to be low or the level of dietary antioxidants is high, because the oxidative status (total antioxidant capacity) is balanced. In this case, up-regulation of antioxidant enzymes has not been required, and the depletion of antioxidants is low (Costantini and Verhulst, 2009; Monaghan et al., 2009); therefore, they are available for self-maintenance, which reduces the cost of coping with oxidative damage (Isaksson et al., 2011). The higher antioxidant capacity found in the rural populations (scenario I) could reflect a surplus of dietary antioxidants, probably due to the availability of some dietary antioxidant complements such as vitamins or minerals. Based on the antioxidant capacity found in suburban birds, the pool of antioxidants must be lower or, probably, oxidative damage increases with urbanization process (scenario II) (Costantini et al., 2014; Isaksson, 2015). In both cases (rural and suburban areas), the maintenance of the oxidative balance would not be costly for individuals, and a reproductive investment should not represent an additional challenge for coping with the oxidative balance (Alonso-Alvarez et al., 2004; Wiersma et al., 2004).

On the other hand, the increasing oxidative damage scenario (III) is in accordance with the results found in urban areas. The oxidative damage in lipids, proteins, and GPX activity showed higher values than those in rural and suburban populations; and the antioxidant capacity of urban birds was lower, especially during the breeding season. These results were expected and in line with a previous study which also found a lower TAC linked to urban areas (Herrera-Dueñas et al., 2014). Here, we propose that pollution could be responsible for the variation in oxidative stress balance between urban and rural areas. For instance, major atmospheric pollutants, such as particles (PM) or heavy metals, have been described as pro-oxidant elements (Kelly, 2003; Isaksson, 2010; Koivula and Eeva, 2010) and their deleterious effects on oxidative stress balance have been described in some urban birds such as Great Tits (Parus major L.) (Koivula et al., 2011), Feral Pidgeon (Columba livia L.) (Kurhalyuk et al., 2009), White Stork (Ciconia ciconia L.) (Kaminski et al., 2007). Similar results have also been found in humans (Chuang et al., 2007; Moller et al., 2014). Therefore, the quantification of these pollutants in the blood or feathers of our populations of House Sparrow may be a useful parameter to confirm this hypothesis in the future.

The lower response to TAC in the urban population is also in line with previous studies that reported poor quality of urban food in terms of antioxidant levels such as carotenoids, vitamins, and minerals (Isaksson and Andersson, 2007; Isaksson, 2015; Tryjanowski et al., 2015). In other urban species like Blackbirds (Turdus merula L.), it has been reported that rural populations showed higher concentrations of vitamin $\mathrm{E}$ and carotenoids than their urban conspecifics, mainly caused by differences in their diet (Moller et al., 2010). Additional studies about the quality of diet in urban birds and its effects on oxidative stress balance could contribute to verifying this theory. 
Under pro-oxidant conditions, the up-regulation of antioxidant enzymes may be required and dietary antioxidants may be depleted; both mechanisms entail some costs (Dowling and Simmons, 2009; Isaksson et al., 2011), which may reduce the fitness and reproductive performance of urban birds (Isaksson, 2015). This is a costly status for individuals, as they must allocate all available resources to counteract the oxidative stress imbalance (Costantini and Verhulst, 2009; Monaghan et al., 2009; Isaksson, 2015). The lack of dietary antioxidants during the breeding season in a challenging environment such as an urban area could lead to potentially negative carry-over effects, in nestlings, linked to early-life nutritional constraints (Metcalfe and Monaghan, 2001). It has been widely reported that the poor condition of House Sparrows nestlings in urban areas is linked to a nutritional deficit (Liker et al., 2008; Bókony et al., 2010; Seress et al., 2012; Meillère et al., 2015). Furthermore, an early-life diet that is poor in antioxidants can result in a long-term impairment in the capacity to assimilate dietary antioxidants, like the carotenoids, vitamin $\mathrm{A}$ and $\mathrm{E}$ in adulthood (Blount et al., 2003; Monaghan et al., 2009; Costantini et al., 2014). Nutritional constraints in early-life further interact to shape the organization of the redox system (Costantini et al., 2014), which could may explain the lack of the antioxidant capacity that we have found in the adults from our urban populations which could be due to the important role that epigenetic mechanism seem to play in the final modulation of oxidative status (Isaksson, 2015).

In our study, we found that rural birds showed better body condition in comparison with their conspecifics in other areas, especially the urban individuals. This result is consistent with the hypothesis of Shochat (2004) in which birds from urban environments show a poorer condition than conspecifics rural birds; and according to previous studies that found these differences between urban and rural populations of House Sparrow (Vincent, 2005; Liker et al., 2008; Bókony et al., 2010; Seress et al., 2012; Herrera-Dueñas et al., 2014). The weak condition of urban birds may be also linked to the nutritional constraints that they suffer during early-life, which could negatively affect body condition in adulthood (Bókony et al., 2010; Seress et al., 2012), even if the restriction diminish at later life stages (Liker et al., 2008). Body condition, especially during development, is often positively correlated with pre- and post-fledgling survival rates (Lamb et al., 2016); consequently, poor condition is often observed in a declining population such as urban House Sparrows (Dulisz et al., 2016).

\section{REFERENCES}

Alonso-Alvarez, C., Bertrand, S., Devevey, G., Prost, J., Faivre, B., and Sorci, G. (2004). Increased susceptibility to oxidative stress as a proximate cost of reproduction: oxidative stress as a cost of reproduction. Ecol. Lett. 7, 363-368. doi: 10.1111/j.1461-0248.2004.00594.x

Anderson, T. (2006). Biology of the Ubiquitous House Sparrow: From Genes to Populations. New York, NY: Oxford University Press.

Andersson, M. N., Wang, H.-L., Nord, A., Salmón, P., and Isaksson, C. (2015). Composition of physiologically important fatty acids in great tits differs
Apart from the direct effects of poor diet and pollution on oxidative stress, we should also consider that natural selection may have favored different phenotypes in urban and rural populations. For instance, it has been reported that expression of genes that code for metal detoxification enzymes are upregulated in urban populations of Great Tits (Parus major L.) in comparison with rural ones. Therefore, epigenetic mechanisms could generate life-long changes in gene expression, and subsequently, phenotypic traits between urban and rural populations (Watson et al., 2017).

Our study has revealed the fragile oxidative stress balance of the urban House Sparrow, promoted either by an excess of harmful free radicals due to pollution, or insufficient antioxidants due to scarce availability of dietary antioxidants, or both in urban environments. Therefore, birds need to invest resources in maintaining the oxidative stress balance, which is costly especially during the breeding season, when the constraints of antioxidants could entail negative consequences not only on the body condition of the individuals, but also on the viability and future fitness of their offspring. The accumulative effects of lower quality individuals and carry over effects at the population level may be one of the causes underlying the population decreases of urban House Sparrow populations across European cities.

\section{AUTHOR CONTRIBUTIONS}

JA, MA, JP, and AH conceived and designed the study. JA, JP, and AH performed the fieldwork. JP and AH conducted lab work. AH performed statistical analyses with support from JP. AH drafted the manuscript and all the authors contributing to the final text.

\section{ACKNOWLEDGMENTS}

We acknowledge Comunidad de Madrid and Junta de Extremadura for issuing the permissions, and the CMA for the ringing license. We are grateful to Javier de la Puente, Álex García, Yaiza Aragón, Eva Banda, Alicia Jacoste, and Juan from the Royal Palace of Madrid staff, people from Olmeda de la Fuentes and people from Plasenzuela for their assistance during fieldwork; and to Pablo S. and Pablo C. for their assistance during ringing training of AHD. We are also grateful to Javier Pérez-Tris lab for its financial support, and Jasper vH. and Melinda H. for improving this manuscript. Finally, we thank the editors for giving us the opportunity to participate in this issue, and the two reviewers who have contributed to improving this manuscript. between urban and rural populations on a seasonal basis. Front. Ecol. Evol. 3:93. doi: 10.3389/fevo.2015.00093

Arnal, N., de Alaniz, M. J. T., and Marra, C. A. (2011). Carnosine and neocuproine as neutralizing agents for copper overload-induced damages in cultured human cells. Chem. Biol. Interact. 192, 257-263. doi: 10.1016/j.cbi.2011.03.017

Benzie, I. F., and Strain, J. J. (1996). The ferric reducing ability of plasma (FRAP) as a measure of "antioxidant power": the FRAP assay. Anal. Biochem. 239, 70-76. doi: 10.1006/abio.1996.0292

Berglund, Å. M. M., Rainio, M. J., Kanerva, M., Nikinmaa, M., and Eeva, T. (2014). Antioxidant status in relation to age, condition, reproductive 
performance and pollution in three passerine species. J. Avian Biol. 45, 235-246. doi: 10.1111/j.1600-048X.2013.00126.X

Blount, J. D., Metcalfe, N. B., Arnold, K. E., Surai, P. F., Devevey, G. L., and Monaghan, P. (2003). Neonatal nutrition, adult antioxidant defences and sexual attractiveness in the zebra finch. Proc. R. Soc. B 270, 1691-1696. doi: $10.1098 / \mathrm{rspb} .2003 .2411$

Bókony, V., Kulcsár, A., and Liker, A. (2010). Does urbanization select for weak competitors in house sparrows? Oikos 119, 437-444. doi: 10.1111/j.1600-0706. 2009.17848.x

Chuang, K.-J., Chan, C.-C., Su, T.-C., Lee, C.-T., and Tang, C.-S. (2007). The effect of urban air pollution on inflammation, oxidative stress, coagulation, and autonomic dysfunction in young adults. Am. J. Respir. Crit. Care Med. 176, 370-376. doi: 10.1164/rccm.200611-1627OC

Costantini, D. (2011). On the measurement of circulating antioxidant capacity and the nightmare of uric acid: antioxidant capacity and uric acid. Methods Ecol. Evol. 2, 321-325. doi: 10.1111/j.2041-210X.2010.00080.x

Costantini, D., Greives, T. J., Hau, M., and Partecke, J. (2014). Does urban life change blood oxidative status in birds? J. Exp. Biol. 217, 2994-2997. doi: 10.1242/jeb.106450

Costantini, D., and Verhulst, S. (2009). Does high antioxidant capacity indicate low oxidative stress? Funct. Ecol. 23, 506-509. doi: 10.1111/j.1365-2435. 2009.01546.x

De Coster, G., De Laet, J., Vangestel, C., Adriaensen, F., and Lens, L. (2015). Citizen science in action-evidence for long-term, region-wide house sparrow declines in Flanders, Belgium. Landscape Urban Plan. 134, 139-146. doi: 10.1016/j.landurbplan.2014.10.020

De Laet, J., and Summers-Smith, J. D. (2007). The status of the urban house sparrow Passer domesticus in north-western Europe: a review. J. Ornithol. 148, 275-278. doi: 10.1007/s10336-007-0154-0

Dowling, D. K., and Simmons, L. W. (2009). Reactive oxygen species as universal constraints in life-history evolution. Proc. Biol. Sci. 276, 1737-1745. doi: $10.1098 /$ rspb.2008.1791

Dulisz, B., Nowakowski, J. J., and Górnik, J. (2016). Differences in biometry and body condition of the house sparrow (Passer domesticus) in urban and rural population during breeding season. Urban Ecosyst. 19, 1307-1324. doi: 10.1007/s11252-016-0546-0

Evans, B. S., Ryder, T. B., Reitsma, R., Hurlbert, A. H., and Marra, P. P. (2015). Characterizing avian survival along a rural-to-urban land use gradient. Ecology 96, 1631-1640. doi: 10.1890/14-0171.1

Evans, K. L., Chamberlain, D. E., Hatchwell, B. J., Gregory, R. D., and Gaston, K. J. (2011). What makes an urban bird? Glob. Change Biol. 17, 32-44. doi: 10.1111/j.1365-2486.2010.02247.x

Forman, R. T. T. (2013). Urban Ecology: Science of Cities. Cambridge: Cambridge University Press.

Fossati, P., Prencipe, L., and Berti, G. (1980). Use of 3,5-dichloro-2hydroxybenzenesulfonic acid/4-aminophenazone chromogenic system in direct enzymic assay of uric acid in serum and urine. Clin. Chem. 26, 227-231.

Gaston, K. J. (ed.). (2010). Urban Ecology. Cambridge: Cambridge University Press.

Gil, D., and Brumm, H. (eds.) (2014). Avian Urban Ecology: Behavioural and Physiological Adaptations. Oxford; New York, NY: Oxford University Press.

Grimm, N. B., Faeth, S. H., Golubiewski, N. E., Redman, C. L., Wu, J., Bai, X., et al. (2008). Global change and the ecology of cities. Science 319, 756-760. doi: 10.1126/science. 1150195

Grotto, D., Maria, L. S., Valentini, J., Paniz, C., Schmitt, G., Garcia, S. C., et al. (2009). Importance of the lipid peroxidation biomarkers and methodological aspects for malondialdehyde quantification. Quim. Nova 32, 169-174. doi: 10.1590/S0100-40422009000100032

Halliwell, B. (2007). Biochemistry of oxidative stress. Biochem. Soc. Trans. 35, 1147-1150. doi: 10.1042/BST0351147

Hargitai, R., Costantini, D., Moskát, C., Bán, M., Muriel, J., and Hauber, M. E. (2012). Variation in plasma oxidative status and testosterone level in relation to egg-eviction effort and age of brood-parasitic common cuckoo nestlings. Condor 114, 782-791. doi: 10.1525/cond.2012.110166

Herrera-Dueñas, A., Pineda, J., Antonio, M. T., and Aguirre, J. I. (2014). Oxidative stress of house sparrow as bioindicator of urban pollution. Ecol. Indic. 42, 6-9. doi: 10.1016/j.ecolind.2013.08.014

Isaksson, C. (2010). Pollution and its impact on wild animals: a meta-analysis on oxidative stress. Ecohealth 7, 342-350. doi: 10.1007/s10393-010-0345-7
Isaksson, C. (2015). Urbanization, oxidative stress and inflammation: a question of evolving, acclimatizing or coping with urban environmental stress. Funct. Ecol. 29, 913-923. doi: 10.1111/1365-2435.12477

Isaksson, C., and Andersson, S. (2007). Carotenoid diet and nestling provisioning in urban and rural great tits Parus major. J. Avian Biol. 38, 564-572. doi: 10.1111/j.0908-8857.2007.04030.x

Isaksson, C., Sheldon, B. C., and Uller, T. (2011). The challenges of integrating oxidative stress into life-history biology. BioScience 61, 194-202. doi: 10.1525/bio.2011.61.3.5

Kaminski, P., Kurhalyuk, N., and Szady-Grad, M. (2007). Heavy metal-induced oxidative stress and changes in physiological process of free radicals in the blood of white stork (Ciconia ciconia) chicks in polluted areas. Pol. J. Environ. Stud. 16, 555-562.

Kark, S., Iwaniuk, A., Schalimtzek, A., and Banker, E. (2007). Living in the city: can anyone become an 'urban exploiter'? J. Biogeogr. 34, 638-651. doi: $10.1111 /$ j.1365-2699.2006.01638.x

Kelly, F. J. (2003). Oxidative stress: its role in air pollution and adverse health effects. J. Occup. Environ. Med. 60, 612-616. doi: 10.1136/oem.60.8.612

Koivula, M. J., and Eeva, T. (2010). Metal-related oxidative stress in birds. Environ. Pollut. 158, 2359-2370. doi: 10.1016/j.envpol.2010.03.013

Koivula, M. J., Kanerva, M., Salminen, J.-P., Nikinmaa, M., and Eeva, T. (2011). Metal pollution indirectly increases oxidative stress in great tit (Parus major) nestlings. Environ. Res. 111, 362-370. doi: 10.1016/j.envres.2011.01.005

Kurhalyuk, N., Hetmanski, T., Antonowicz, J., and Tkachenko, H. (2009). Oxidative stress and protein oxidation affected by toxic metals in feral pigeon (Columba livia) from Northern Poland. Baltic Coastal Zone. J. Ecol. Prot. Coastline 13, 187-197.

Lamb, J. S., O’Reilly, K. M., and Jodice, P. G. R. (2016). Physical condition and stress levels during early development reflect feeding rates and predict preand post-fledging survival in a nearshore seabird. Conserv. Physiol. 4:cow060. doi: 10.1093/conphys/cow060

Lepczyck, C. A., and Warren, P. S. (eds.). (2012). Urban Bird Ecology and Conservation. Berkeley, CA: University of California Press.

Liker, A., Papp, Z., Bókony, V., and Lendvaiá, Z. (2008). Lean birds in the city: body size and condition of house sparrows along the urbanization gradient. J. Anim. Ecol. 77, 789-795. doi: 10.1111/j.1365-2656.2008.01402.x

Marklund, S., and Marklund, G. (1974). Involvement of the superoxide anion radical in the autoxidation of pyrogallol and a convenient assay for superoxide dismutase. Eur. J. Biochem. 47, 469-474. doi: 10.1111/j.1432-1033.1974.tb03714.x

Marzluff, J. M. (ed.) (2008). Urban Ecology: An International Perspective on the Interaction between Humans and Nature. New York, NY: Springer.

Marzluff, J. M. (2016). A decadal review of urban ornithology and a prospectus for the future. Ibis 159, 1-13. doi: 10.1111/ibi.12430

Meillère, A., Brischoux, F., Parenteau, C., and Angelier, F. (2015). Influence of urbanization on body size, condition, and physiology in an urban exploiter: a multi-component approach. PLoS ONE 10:e0135685. doi: 10.1371/journal.pone.0135685

Metcalfe, N. B., and Monaghan, P. (2001). Compensation for a bad start: grow now, pay later? Trend. Ecol. Evol. 16, 254-260. doi: 10.1016/S0169-5347(01)02124-3

Moller, A. P., Erritzøe, J., and Karadas, F. (2010). Levels of antioxidants in rural and urban birds and their consequences. Oecologia 163, 35-45. doi: 10.1007/s00442-009-1525-4

Moller, P., Danielsen, P. H., Karottki, D. G., Jantzen, K., Roursgaard, M., Klingberg, H., et al. (2014). Oxidative stress and inflammation generated DNA damage by exposure to air pollution particles. Mutat. Res. Rev. Mutat. Res. 762, 133-166. doi: 10.1016/j.mrrev.2014.09.001

Monaghan, P., Metcalfe, N. B., and Torres, R. (2009). Oxidative stress as a mediator of life history trade-offs: mechanisms, measurements and interpretation. Ecol. Lett. 12, 75-92. doi: 10.1111/j.1461-0248.2008.01258.x

Niemelä, J. (ed.) (2011). Urban Ecology: Patterns, Processes, and Applications. Oxford; New York, NY: Oxford University Press.

Ohkawa, H., Ohishi, N., and Yagi, K. (1979). Assay for lipid peroxides in animal tissues by thiobarbituric acid reaction. Anal. Biochem. 95, 351-358. doi: 10.1016/0003-2697(79)90738-3

Oro, D., Genovart, M., Tavecchia, G., Fowler, M. S., and Martínez-Abraín, A. (2013). Ecological and evolutionary implications of food subsidies from humans. Ecol. Lett. 16, 1501-1514. doi: 10.1111/ele.12187 
Peach, W. J., Vincent, K. E., Fowler, J. A., and Grice, P. V. (2008). Reproductive success of house sparrows along an urban gradient. Anim. Conserv. 11, 493-503. doi: 10.1111/j.1469-1795.2008.00209.x

Peig, J., and Green, A. J. (2009). New perspectives for estimating body condition from mass/length data: the scaled mass index as an alternative method. Oikos 118, 1883-1891. doi: 10.1111/j.1600-0706.2009.17643.x

Reznick, A. Z., and Packer, L. (1994). Oxidative damage to proteins: spectrophotometric method for carbonyl assay. Methods Enzymol. 233, 357-363. doi: 10.1016/S0076-6879(94)33041-7

Romero-Haro, A. A., Sorci, G., and Alonso-Alvarez, C. (2016). The oxidative cost of reproduction depends on early development oxidative stress and sex in a bird species. Proc. R. Soc. B 283:20160842. doi: 10.1098/rspb.2016.0842

Salmón, P., Nilsson, J. F., Nord, A., Bensch, S., and Isaksson, C. (2016). Urban environment shortens telomere length in nestling great tits, Parus major. Biol. Lett. 12:20160155. doi: 10.1098/rsbl.2016.0155

Seress, G., Bókony, V., Pipoly, I., Szép, T., Nagy, K., and Liker, A. (2012). Urbanization, nestling growth and reproductive success in a moderately declining house sparrow population. J. Avian Biol. 43, 403-414. doi: 10.1111/j.1600-048X.2012.05527.x

Shaw, L. M., Chamberlain, D., and Evans, M. (2008). The house sparrow Passer domesticus in urban areas: reviewing a possible link between post-decline distribution and human socioeconomic status. J. Ornithol. 149, 293-299. doi: $10.1007 / \mathrm{s} 10336-008-0285-\mathrm{y}$

Shochat, E. (2004). Credit or debit? Resource input changes population dynamics of city-slicker birds. Oikos 106, 622-626. doi: 10.1111/j.0030-1299.2004.13159.x

Tkachenko, H., Kurhaluk, N., Grudniewska, J., and Andriichuk, A. (2014). Tissuespecific responses of oxidative stress biomarkers and antioxidant defenses in rainbow trout Oncorhynchus mykiss during a vaccination against furunculosis. Fish Physiol. Biochem. 40, 1289-1300. doi: 10.1007/s10695-014-9924-9
Tryjanowski, P., Skórka, P., Sparks, T. H., Biaduń, W., Brauze, T., Hetmański, T., et al. (2015). Urban and rural habitats differ in number and type of bird feeders and in bird species consuming supplementary food. Environ. Sci. Pollut. Res. 22, 15097-15103. doi: 10.1007/s11356-0154723-0

Vincent, K. E. (2005). Investigating the Causes of the Decline of the Urban House Sparrow Passer Domesticus Population in Britain. Thesis, De Monfort University, Leicester, UK.

Watson, H., Videvall, E., Andersson, M. N., and Isaksson, C. (2017). Transcriptome analysis of a wild bird reveals physiological responses to the urban environment. Sci. Rep. 7:44180. doi: 10.1038/srep44180

Wiersma, P., Selman, C., Speakman, J. R., and Verhulst, S. (2004). Birds sacrifice oxidative protection for reproduction. Proc. R. Soc. B 271, S360-S363. doi: $10.1098 /$ rsbl.2004.0171

Zeb, A., and Ullah, F. (2016). A simple spectrophotometric method for the determination of thiobarbituric acid reactive substances in fried fast foods. $J$. Anal. Methods Chem. 2016, 1-5. doi: 10.1155/2016/9412767

Conflict of Interest Statement: The authors declare that the research was conducted in the absence of any commercial or financial relationships that could be construed as a potential conflict of interest.

Copyright (c) 2017 Herrera-Dueñas, Pineda-Pampliega, Antonio-García and Aguirre. This is an open-access article distributed under the terms of the Creative Commons Attribution License (CC BY). The use, distribution or reproduction in other forums is permitted, provided the original author(s) or licensor are credited and that the original publication in this journal is cited, in accordance with accepted academic practice. No use, distribution or reproduction is permitted which does not comply with these terms. 